\title{
La ironía de la solidaridad: cultura, sociedad civil y discursos sobre el conflicto racial de El Ejido
}

\author{
Eduardo Terrén \\ Universidade da Coruña
}

\section{RESUMEN}

El objetivo de este trabajo es explorar el potencial analítico de un programa fuerte de sociología cultural a la hora de estudiar cómo la sociedad civil responde ante un fenómeno de conflicto racial (los disturbios de El Ejido de febrero de 2000). El estudio muestra cómo en el ámbito de la sociedad civil pueden surgir discursos que, aun proporcionando una narrativa diferente del conflicto, reproducen un mismo código semiótico profundo caracterizado fundamentalmente por ser una estructura de clasificación binaria y albergar una inherente dialéctica de inclusión y exclusión. Este código dicotómico puede considerarse como la estructura simbólica de la cultura política de la sociedad civil. El análisis de los discursos que compiten por la autoridad interpretativa de un conflicto racial desde una perspectiva derivada de la teoría de la religión de Durkheim permite, así, mostrar la ironía de que la producción de los afectos y compromisos civiles implicados en las narrativas de la solidaridad social sea inseparable de una representación polarizada del «ellos» y del «nosotros» bajo la forma de lo sagrado y lo profano. El potencial analítico de esta perspectiva teórica permite, en definitiva, subrayar la estrecha relación que guarda la producción discursiva de la solidaridad con la estructura de clasificación del mundo social y la dificultad que esto entraña para pensar la sociedad civil como una comunidad moral global.

Palabras clave: Conflictos Étnicos, Sociología de la Cultura, Semiótica, Sociedad Civil. 


\section{ORGANIZACIÓN INTERNA Y DINÁMICA DE LOS SISTEMAS CULTURALES: LA CULTURA COMO CONTEXTO INTERNO DE LA ACCIÓN}

Desde las últimas dos décadas del siglo pasado el análisis cultural ha pasado a ocupar un lugar central en la investigación y el debate sociológicos. La renovada centralidad de la dimensión simbólica del orden social va de la mano de la percepción de que la cultura está desempeñando un papel sin precedentes en la configuración de la vida social actual. Nash (2001) ha descrito este punto como el momento de un «giro cultural» de la teoría sociológica. En su opinión, este giro se caracteriza por la convergencia de planteamientos que coinciden en no reconocer la estructura social como determinante último de la cultura, sino, más bien, como algo culturalmente construido, y en esforzarse por analizar la lógica interna de la reproducción cultural más allá del modelo simple del reflejo ideológico y del interés de la clase dominante.

El programa fuerte de sociología cultural defendido por Jeffrey Alexander — curiosamente, no mencionado en el balance de Nash — puede considerarse también como exponente de este giro cultural. Dicho programa se presenta como respuesta a la necesidad de reconducir un análisis sociológico al que se considera sesgado en su consideración de lo cultural debido a una tradicional «insensibilidad respecto al significado» (Alexander, 2000a: 41s) que le ha llevado a fagocitar el «poder estructurante de lo sagrado y lo profano». Se consideran éstas dimensiones fundamentales de una esfera cultural que tiene entidad por sí misma y que no es reducible analítica ni ontológicamente a ninguna otra esfera de la actividad humana, por muy interrelacionada que esté con cualquiera de ellas. En los términos propios de este programa, la atención a dicho carácter estructurante de lo sagrado y lo profano equivale a la defensa de la autonomía de la cultura, que se constituye, así, en la auténtica piedra angular de su entramado teórico'.

La defensa de la autonomía relativa de la cultura entronca con la crítica a las visiones mecanicistas y puramente respondentes de una acción entendida como subordinada a un orden objetivo y exterior a ella (Alexander, 1990) y desarrolla la idea del poder estructurante de los sistemas culturales como ámbito compartido de signos e ideas. En este ámbito sim-

\footnotetext{
1 Así, la mayoría de los planteamientos que, de la mano de las teorías neomarxistas de inspiración gramsciana o de la teoría crítica de la cultura de masas, han venido marcando la alternativa a la teoría funcionalista de los valores serían más bien exponentes del «programa débil» de una sociología de la cultura, y no pueden, por tanto, considerarse como verdaderos exponentes de una sociología cultural. Alexander (2000a) distingue el programa fuerte del débil afirmando que hacer una sociología cultural no es lo mismo que hacer una sociología de la cultura. Lo primero implica asumir que la sociología ha de tener necesariamente una dimensión cultural, es decir, que es una ciencia cultural; lo segundo, en cambio, conduce generalmente a reducir lo cultural a otras variables explicativas tradicionalmente entendidas como "variables duras». En relación con ello, se entiende, igualmente, para lo que sigue, que el último Durkheim no intentó desarrollar una sociología de la religión, sino, más bien, una sociología religiosa.
} 
bólico compartido es en el que la perspectiva estructuralista de la sociología cultural tiende a ver la base lógica de los procesos discursivos en los que se gesta la solidaridad social. Aunque la teoría funcionalista de la cultura tuvo para Alexander (1990: 6) la virtud de limar el idealismo de las aproximaciones de corte diltheyano, terminó por erosionar la propia autonomía de la cultura al establecer los valores a partir de una generalización del comportamiento de los grupos, más que a partir de una interpretación de la dinámica interna del propio sistema de la cultura, que es lo que en el fondo ha de perseguir una auténtica sociología cultural. A su juicio, en toda perspectiva puramente funcionalista, el análisis de la cultura queda reducido a un análisis de los valores como significados institucionalizados a través de la socialización y los sistemas normativos de sanción social, lo que —en última instancia — la devuelve a un cierto mecanicismo que deja sin explicar la naturaleza interna de los sistemas de valores (al deducirlos de las necesidades funcionales del sistema) y pierde de vista el poder estructurante de los propios procesos internos del sistema cultural ${ }^{2}$.

Frente a este reduccionismo funcionalista, el programa fuerte de la sociología cultural busca en el estructuralismo saussuriano el referente teórico que necesita para su abordaje de la autonomía de la cultura, y encuentra en el análisis de la religión y las formas primitivas de clasificación del último Durkheim la mejor aplicación al análisis sociológico de dicho marco teórico. Recuérdese cómo, al centrar el objeto de estudio científico de la lingüística en la langue, Saussure privilegió el estudio de la estructura profunda del lenguaje y abrió el camino a una perspectiva semiótica en la que el actor (el hablante), aun siendo responsable de su acción, no tiene control sobre el sistema de reglas (la gramática) que la condicionan. La versión sociológica de este principio consistiría en afirmar que toda acción social (como toda acción lingüística) está enredada en un sistema de signos que cuenta con una estructura profunda relativamente independiente, estructura que sólo puede ser comprendida a través de una reconstrucción interna del código en que se expresa. De ahí que la perspectiva abierta por la semiótica de Saussure sea fundamental para este esfuerzo estructuralista por estudiar la organización interna de los sistemas simbólicos, por cuanto entiende que todo proceso concreto de acción se produce en un marco preexistente de significados que está siempre sistemáticamente organizado según relaciones de analogías y antinomias. La clave de este programa de investigación estriba, pues, en buscar las estructuras latentes que subyacen a las categorizaciones del mundo, entendido que sin esta estructura de clasificación (la organización del mundo en posiciones) no es posible la vida social (Durkheim, 1912/1982: 411).

\footnotetext{
2 Este mismo tipo de déficit en la consideración de la autonomía relativa de la cultura puede apreciarse en el neomarxismo de cuño gramsciano tal y como ha sido desarrollado, por ejemplo, por la Escuela de Birmingham. Así, el tratamiento de los significados como ideologías desarrollado por el marxismo cultural se encuadra siempre en una estructura de dominación de clase que, de forma analíticamente similar al tratamiento parsoniano de los valores, termina forjando un análisis reduccionista de la cultura que impide reconocer en toda su amplitud y profundidad la verdadera dinámica de la autonomía de la cultura.
} 
Este principio analítico debe considerarse en relación con lo que podríamos considerar, al menos para nuestros efectos, uno de los principios sustantivos de la teoría de la sociedad de Durkheim: lo sagrado —como espacio de comunión social- nunca desaparece en el curso del cambio social; o, lo que viene a ser lo mismo, la secularización no implica desacralización. Más concretamente, esta especie de estructuralismo religioso de lo social podría sintetizarse en los siguientes puntos: 1) el nacimiento de una nueva forma de solidaridad que acompaña al cambio social disuelve el tipo de vida moral característico del orden tradicional precedente, pero no la persistencia misma de una moralidad social que, antes bien, encuentra una nueva expresión en el individualismo moral; 2) la decadencia de la religión (deísta, se entiende) como expresión de esa vida moral no impide que pueda seguirse hablando de la religión (civil, en este caso) como espacio cultural en el que se reproducen las significaciones asociadas a esa nueva solidaridad; y 3) consiguientemente, la dinámica de los procesos culturales asociados a esta solidaridad debe ser analizada en relación con la estructura simbólica profunda de la que se nutre en última instancia toda clasificación social: la dicotomía de lo sagrado y lo profano ${ }^{3}$.

Así, pues, la impronta estructuralista del programa fuerte de la sociología cultural deriva de esta recepción de la sociología religiosa del último Durkheim tal y como ha sido revisada por Alexander (1988), Swidler (1986) o Emirbayer (1996), siguiendo en gran medida la estela de los trabajos realizados dos décadas antes por Edward Shils, Robert Bellah o Mary Douglas, coincidentes en señalar al binarismo de lo sagrado y lo profano no sólo como fuerzas de clasificación, sino también como fuentes de compromiso moral hacia el polo puro o centro simbólico de la religión civil que permite la sacralización de la politeya secular (Giner, 1996). Este desarrollo de la teoría de la cultura del último Durkheim compartiría con la perspectiva de la semiótica estructural de Saussure el interés por contemplar los sistemas culturales como organizaciones de antinomias simbólicas. Para Durkheim, sin embargo, estas antinomias no resultaban de una mera contraposición lógica, sino de una antítesis fundamental entre los principios clasificadores de lo sagrado y lo profano, en cuya articulación creía Durkheim ver la base de la organización de la vida social. Es la autonomía relativa de la cultura entendida como estructura semiótica subyacente lo que permite desarrollar un análisis sociológico que: 1) prima el análisis de los fenómenos simbólicos y de su organización interna, y 2) vincula este análisis con la dinámica de la solidaridad so-

\footnotetext{
${ }^{3}$ En cuanto que categorías de clasificación, las categorías son herramientas —afirma Durkheim (1912/1982: 17)—, instituciones mentales que acumulan capital intelectual y proporcionan la base lógica de la moralidad (no la moralidad misma). Nacen de la religión porque la forma en que ésta clasifica las cosas del mundo en dos esferas heterogéneas supone la base de todo conocimiento: las formas en que se puede expresar este contraste son variables, pero «el hecho mismo del contraste es universal» (1912/1982: 35). Quizá no esté de más señalar que dicho contraste no establece una mera separación, sino un antagonismo entre mundos hostiles entre sí que exigen pertenencias excluyentes. Este antagonismo deriva de la propia esencia de lo sagrado como diferencia sobrepuesta al ámbito empírico (como «diferencia establecida en el orden del ser», en palabras de Ramos, 1999: 206).
} 
cial. Es importante señalar también, no obstante, que (siguiendo la forma en que Alexander se distancia del estructuralismo de Lévy-Strauss) esta defensa del valor de la cultura como objeto de investigación autónomo no equivale a entenderla como una lógica meramente abstracta que llegue a dotar a los códigos de capacidad causal. Al contrario, lo que persigue el programa fuerte de la sociología cultural es conseguir "descripciones densas» (Geertz, 1989) de cómo la cultura interviene en la configuración de las acciones a través no sólo de los códigos subyacentes que estructuran las redes de significados, sino también de las narrativas que dan vida «real» a dichas redes ${ }^{4}$.

\section{INCLUSIÓNY EXCLUSIÓN EN LA ESTRUCTURA SIMBÓLICA DE LA SOCIEDAD CIVIL}

El estudio de la sociedad civil puede considerarse como un caso concreto de aplicación empírica de los presupuestos del programa fuerte de la sociología cultural en la medida en que al considerarla como objeto de análisis sociológico se proyecta sobre ella la misma operación de «epojé hermenéutica» que se considera precisa para un tratamiento adecuado de la cultura como entidad relativamente autónoma ${ }^{5}$. Así, análogamente a como la cultura puede aislarse analíticamente para descubrir su estructura semiótica latente, «el lenguaje que configura el núcleo cultural de la sociedad civil puede aislarse como una estructura general y estudiarse como una forma simbólica relativamente autónoma» (Alexander, 2000b: 145).

Al considerar la sociedad civil no tanto como un tipo ideal cuanto como un objeto de investigación empírica, lo que interesa analizar es la producción de ese cemento emocional y moral de la integración social que constituye la solidaridad. Se considera, así, que el desarrollo de la esfera pública es parte fundamental de la constitución de una sociedad civil y que dicho desarrollo puede analizarse a partir de las narrativas con las que se construyen los sentimientos de pertenencia a través de los que fluye buena parte de la solidaridad so-

\footnotetext{
4 La orientación de la teoría sociológica implícita en el programa fuerte de la sociología cultural guarda, así, una estrecha afinidad con la teoría de la interpretación cultural de Geertz, pues — como éste afirmó (1989: 36) — «la tarea esencial en la elaboración de una teoría, es, no codificar regularidades abstractas, sino hacer posible la descripción densa», una expresión que Geertz tomó de Ryle y que se refiere al desentrañamiento de las estructuras de significación que se superponen en la acción analizada. El modelo de este análisis es la lectura «en el sentido de interpretar un texto» (Geertz, 1989: 24), analogía que Alexander mantiene basándose a su vez en la idea de la acción significativa como texto (Ricoeur, 1971) y negando que el papel de la sociología deba reducirse a proporcionar contextos.

5 Alexander (2000a: 33) habla de un compromiso de la sociología cultural con el «momento hermenéutico» que toma su modelo del análisis fenomenológico de la estructura de la conciencia. Así como éste "pone entre paréntesis» lo dado objetivamente para descubrir la estructura y el poder constituyente de la subjetividad trascendental, aquélla debe poner entre paréntesis el contexto objetivo del significado para poder captar su código y su articulación narrativa.
} 
cial elaborada en los discursos que atraviesan la esfera pública. Por eso, como señala Pérez Díaz (1998: 215), gran parte de los debates de la esfera pública giran en torno a sentimientos de pertenencia basados en experiencias compartidas de necesidad y de obligación recíprocas que emergen de intercambios políticos y económicos, pero que «obtienen significado en el marco de narrativas estructuradas en torno a vinculaciones primordiales o quasiprimordiales».

El programa fuerte de la sociología cultural ha pretendido un mayor rigor y un mayor realismo a la hora de trasladar el concepto de sociedad civil desde el nivel de la discusión normativa al de su aplicación empírica. Ello le ha llevado a hablar de «sociedades civiles reales» (Alexander, 1998) o «sociedades civiles particulares» (Pérez Díaz, 1998: 215) y, en definitiva, a reconocer la esfera de la sociedad civil como un ámbito complejo en el que la pluralidad de discursos producida por las diferentes comunidades interpretativas genera una «tensión esencial» en la vida pública. Como esperamos mostrar a través del caso concreto analizado en la sección siguiente, la dinámica de esta tensión es accesible a través del estudio de las narrativas que compiten entre sí por la autoridad interpretativa sobre los hechos públicos. No obstante, la «descripción densa» de la dinámica de estas estructuras temporales debe ser puesta en relación con el código común subyacente que todas ellas comparten, pues las identificaciones suministradas por todas ellas recurren a un mismo patrón discursivo polarizante a la hora de construir sus representaciones populares del bien y del $\mathrm{mal}^{6}$. Este código constituye la estructura simbólica profunda de la cultura política de la sociedad civil.

El acercamiento durkheimiano a la cultura de la sociedad civil propuesto por el programa fuerte de la sociología cultural la concibe como un sistema de significados semióticamente conformada en torno al binarismo fundamental de la civilidad y la barbarie, binarismo universal en el que se expresa la dialéctica del bien y el mal en todo discurso cívico (Smith, 1998: 118). A partir de lo expuesto en el apartado anterior, debe verse claramente cómo el carácter binario de esta estructura remite a esa perspectiva durkheimiana que hace de la polarización entre lo sagrado y lo profano una dimensión esencial de la representación organizada que subyace a toda forma de comunión social ${ }^{7}$. Lo que interesa ahora es ver cómo, trasladada al ámbito de la sociedad civil, esta perspectiva permite ver la forma en

6 «El empleo social de las identificaciones simbólicas polarizadoras debe entenderse desde la estructura interna del discurso mismo [de la sociedad civil]» (Alexander, 2000b: 160).

\footnotetext{
7 No obstante — como me ha hecho observar Ramón Ramos—, a pesar de su carácter fundante, la polaridad sagrado/profano no agota en sí misma la dialéctica entre clasificación y socialidad. Como él mismo destaca (Ramos, 1999: 207), el análisis durkheimiano de los ritos piaculares (Durkheim, 1912/1982: 369-385) —al que Alexander no presta atención— muestra una ambigüedad de lo sagrado al poder profanarse éste a sí mismo cuando se contagia de lo impuro, de la misma manera en que lo profano puede transformarse en sagrado si llega a inducir respeto.
} 
que el discurso de la ciudadanía alberga una tensión inherente entre inclusión y exclusión, pues - de forma análoga al hecho de que lo sagrado no pueda representarse sin lo profano- la producción de un código lleva aparejada la de un contracódigo: toda propuesta moral, cognitiva y afectiva precisa en el fondo de la producción de su antítesis. Así, al mismo tiempo que a través del primero se alimenta el sentimiento de compromiso con los iguales a los que se les reconoce la pertenencia, a través del segundo se alimenta el sentimiento de amenaza frente a los que son considerados como un peligro para lo que el primero sacraliza. Por eso, la tendencia a la universalización de las motivaciones, relaciones e instituciones amparadas por el polo positivo coexiste en el discurso de la sociedad civil con las tendencias particularizadoras. Si la esfera de la sociedad civil es un foco de producción discursiva de solidaridad social, la estructura dicotómica de su código latente explicaría por qué esa solidaridad debe construirse tanto por referencia a lo que incluye como a lo que excluye. Para Alexander (2000b: 142), efectivamente, la sociedad civil es «una esfera de solidaridad en la que el universalismo abstracto y las versiones particularistas de la sociedad se muestran tensionalmente entrelazadas».

Más allá de su dimensión institucional, la sociedad civil tiene también una dimensión subjetiva constituida por un «entramado de comprensiones» limitadas y posibilitadas a un mismo tiempo por el código simbólico que estructura las categorías clasificatorias del mundo. El análisis de esta dimensión subjetiva es decisivo para entender la importancia que tiene la cuestión de la afiliación en la producción de la solidaridad social, pues el problema de «identificar a la gente» (Calhoun, 1993: 343) que puede ser miembro de una vida pública común es un elemento esencial del proceso de «comunalización de la sociedad» 8 . Determinar quién es de los nuestros y quién no es resultado de una gestión de la afiliación que no por ser históricamente variable puede escapar a la gramática profunda de un código sistemático. Este código es el que establece las diferencias entre la virtud y el vicio cívicos en un mismo núcleo cultural relativamente autónomo (y analíticamente aislable) que constituye la estructura simbólica de la solidaridad producida por la sociedad civil. El núcleo presenta la forma recogida en el cuadro 1 (extractado de Alexander, 2000b) ${ }^{9}$.

\footnotetext{
8 Puede evitarse, así, la tendencia a sostener una cierta aceptación edulcorada del concepto de sociedad civil que lleva a asociarlo de una forma excesivamente simple con una esfera de inherente humanización frente a los efectos corrosivos del Estado o del mercado (Smith, 1998). El error de este enfoque radica en depender de una idealización estática de lo cultural y en dejar pervivir en él la distinción ya añeja entre la Gesellshaft y la Gemeishaft, cuando lo que realmente interesa no es la distinción entre ambas formas ideales de sociabilidad, sino su conexión concreta: «la comunidad de la sociedad» (Alexander, 1997: 122).

9 El cuadro articula la estructura binaria del núcleo simbólico sobre los tres niveles en que opera. En el nivel de los motivos se contraponen las características que corresponden a los individuos democráticamente orientados con las de los que carecen de esta orientación. Se supone que los primeros son quienes son capaces de entablar el tipo de relaciones abiertas, confiadas y basadas en la deliberación racional que el segundo nivel clasifica como las propias del código de una sociedad democráticamente estructurada, mientras que los segundos son más proclives a las relaciones cerradas, recelosas o de pura enemistad, cualidades todas ellas del contracódigo. Sobre estas dos estructuras de motivos y relaciones se edifican analógamente dos tipos de entramados institucionales.
} 
CUADRO 1

\begin{tabular}{|c|c|c|c|}
\hline & Motivos & Relaciones & Instituciones \\
\hline Código & $\begin{array}{l}\text { activismo } \\
\text { autonomía } \\
\text { racionalidad } \\
\text { autocontrol }\end{array}$ & $\begin{array}{l}\text { apertura } \\
\text { confianza } \\
\text { crítica } \\
\text { amistad }\end{array}$ & $\begin{array}{l}\text { regulación normativa } \\
\text { igualdad } \\
\text { inclusión } \\
\text { contrato }\end{array}$ \\
\hline Contracódigo & $\begin{array}{l}\text { pasividad } \\
\text { dependencia } \\
\text { irracionalidad } \\
\text { excentricidad }\end{array}$ & $\begin{array}{l}\text { cierre } \\
\text { desconfianza } \\
\text { condescendencia } \\
\text { enemistad }\end{array}$ & $\begin{array}{l}\text { arbitrariedad } \\
\text { jerarquía } \\
\text { exclusión } \\
\text { adscripción }\end{array}$ \\
\hline
\end{tabular}

La semiótica de la cultura política de la sociedad civil queda así recogida en este esqueleto que sostiene su estructura simbólica. Sin embargo, los discursos que se producen en el ámbito de la discusión pública no son abstractos, sino concretos; es decir, se producen bajo la forma de las narrativas históricas con las que los individuos construyen sus propios relatos y se insertan en los producidos por las diferentes comunidades interpretativas, narrativas a través de las cuales los individuos y las comunidades forjan sus propias estrategias de identificación y pertenencia: sólo así producen solidaridad social ${ }^{10}$. Lo importante aquí es señalar cómo las diversas narrativas a través de las que se construye la esfera pública de la sociedad civil reproducen tanto el discurso de la libertad y la virtud política basado en las cualidades de la civilidad como el discurso de la represión basado en las cualidades simbólicas anticiviles. Ésta es la gran ironía instalada en el núcleo cultural de la sociedad civil (Alexander, 2000b: 160).

\section{LA ESTRUCTURA SEMIÓTICA DE LOS DISCURSOS SOBRE EL CONFLICTO RACIAL}

Este apartado presenta un análisis comparativo de dos narrativas que se pueden considerar como representativas del discurso de la sociedad civil española ante un conflicto racial que podemos describir como un fenómeno de crisis: los disturbios de El Ejido en los días 5 al 7 de febrero de 2000. El conflicto racial de aquellos días ha sido destacado como señal

\footnotetext{
10 Reexaminando la teoría del conocimiento de Durkheim desde el punto de vista de la pragmática narrativa, los principios de lo sagrado y lo profano no deberían verse sólo como categorías mentales; si su significado es inseparable de su uso, deberían verse también como fuentes de sentimientos morales. Después de todo, estas propuestas — como la de la sociedad civil democrática, por ejemplo- son siempre propuestas de una determinada interacción consciente. Esta interacción debe ser primero representada y la representación implica recursos simbólicos que ya están organizados de antemano en una estructura subyacente de clasificación polarizante que constriñe y, al mismo tiempo, posibilita la producción de los compromisos y de la evaluación que conlleva una interacción.
} 
de «un antes y un después» en la historia del racismo en España ${ }^{11}$, tanto por el hecho de haberse entremezclado en él nuevas y viejas dinámicas — los efectos de la globalización sobre la agricultura y la añeja tradición de la justicia directa, según Gaviria (2001) — como por la recreación simbólica del conflicto en los medios de comunicación, lo que les convirtió también en protagonistas del fenómeno (Calvo Buezas, 2000: 46s). El análisis presentado se inspira en el trabajo de Jacobs $(1996)^{12}$. Al igual que él, pretende mostrar cómo en las narrativas producidas al respecto se despliega un código de idéntica estructura semiótica basado en la contraposición de elementos civiles y anticiviles, código que puede sistematizarse de acuerdo con el binarismo fundamental de la teoría durkheimiana presentada en las secciones anteriores.

Aunque debe tenerse presente que el objeto de este apartado no es el análisis del fenómeno como tal, sino el de los discursos que suscita su interpretación, conviene precisar el tipo de fenómeno que constituye el suceso narrado antes de adentrarnos en el examen de la trama descrita por cada narrativa y en el de los héroes y antihéroes que identifican las variables simbólicas más destacables. Esta precisión se hace tanto más necesaria cuanto que -a diferencia de lo que ocurre en el ámbito académico sajón- el vocabulario asociado a lo «racial» no está suficientemente asentado en nuestra sociología. Debe repararse en primer lugar en que calificar el fenómeno de referencia como un conflicto «racial» no implica aceptar la variable raza como factor independiente, objetivo y causal, pues pertenece ya al conocimiento científico aceptado que el concepto de «raza» no tiene ninguna relevancia taxonómica a la hora de categorizar actitudes o comportamientos de individuos en función de caracteres fenotípicos. Desde el punto de vista de la interacción y la atribución de pertenencias, sin embargo, razas reales y razas imaginadas cumplen un mismo papel en la construcción de la identidad y la diferencia. Calificar una relación social conflictiva como «racial» quiere decir aquí únicamente que los individuos que en ella intervienen albergan algún tipo de conciencia acerca de supuestas diferencias de actitud y comportamiento entre individuos con diferentes características físicas ${ }^{13}$. No toda relación racial es necesariamente conflictiva

\footnotetext{
11 Así lo señala, por ejemplo, Calvo Buezas (2000: 38). El País (7.02.2000), igualmente, hablaba de «la más grave reacción vandálica de acoso y hostigamiento registrada en España contra inmigrantes». Sólo un año antes, el informe de la Comisión Europea contra el Racismo y la Intolerancia (ECRI, 1999) afirmaba que el «racismo violento» no era un fenómeno extendido en España, aunque constataba algunos ataques a viviendas de gitanos y manifestaciones vecinales de protesta contra la presencia de inmigrantes, lo que hacía temer «indicios de un racismo emergente».

12 Jacobs analiza la reconstrucción llevada a cabo por dos periódicos (considerados como exponentes de la mayoría blanca y de la minoría afroamericana) de los casos de la revuelta de Watts en 1965 y las que siguieron al maltrato de Rodney King en 1991.

13 Hacer gravitar al anatagonismo racial en una actitud y una estructura de representaciones y no en una supuesta esencia racial fue la principal aportación de la sociología de las relaciones étnicas puesta en marcha por R. E. Park y la Escuela de Chicago. En la teoría weberiana de las comunidades étnicas puede encontrarse un desarrollo afín que hace hincapié en la naturaleza construida de las relaciones raciales. Para más detalle sobre este punto, véase Terrén (2002a).
} 
o violenta, pero sí invoca siempre los sentimientos y actitudes que refuerzan las distancias sociales y que son característicos de la «conciencia de raza» (Park, 1939/2002).

El conflicto racial es un escenario estelar para observar la relación entre clasificación y solidaridad. Su relevancia como objeto de análisis radica en que, con mayor intensidad seguramente que otros tipos de conflicto, la lucha de significados implícita en un conflicto racial moviliza recursos simbólicamente vinculados a la etnicidad, lo que tiende a favorecer identificaciones del nosotros que pueden restringir notablemente la universalización de la pertenencia y los criterios de comunión o comunización ${ }^{14}$. El análisis de este tipo de conflicto debe permitir observar, pues, cómo, por un lado, la capacidad de producción de solidaridad social por parte de la sociedad civil deriva fundamentalmente del hecho de constituir un espacio de elaboración simbólica de la «notridad» (we-ness) (Alexander, 1997: 119) y, por otro lado, cómo la representación de la comunidad moral global que sugiere el código positivo de lo sagrado sólo inspira obligación mutua si satisface las exigencias que nos plantea la lealtad hacia los nuestros ${ }^{15}$. La «notridad» potencia un sentimiento de conexión con otros miembros de la comunidad cuya construcción simbólica depende de, y al mismo tiempo favorece, el desarrollo de una identidad unificadora. Por eso, la solidaridad que emana del discurso de la sociedad civil tiende a definirse siempre en términos universalizadores (pues sólo así puede generalizarse y trascender las diferencias, los intereses y compromisos individuales que impulsan fuerzas o instituciones particularizadoras). ¿Hasta qué punto, sin embargo, esta tendencia universalizadora está limitada por una estructura simbólica excluyente? Si el desarrollo de la solidaridad social auspiciado por la sociedad civil es capaz de suministrar un sentimiento de seguridad ontológica que, además de a la rutina, está asociado a la continuidad de la identidad (Giddens, 1993) y, por tanto, a un sentimiento de pertenencia que es por definición excluyente, tenemos que el mismo discurso que entrelaza las variables de la inclusión universalizadora alberga en su seno el germen de la exclusión, al menos en un sentido lógico ${ }^{16}$.

\footnotetext{
14 Recuérdese, en este sentido, que para Weber (1974: 318s) la etnicidad es sólo un momento del proceso de comunización (Vergemeischaftung), momento, por lo demás, «artificioso» por cuanto corresponde a la trasposición de socializaciones (Vergesellchaftungen) racionales en relaciones personales de comunidad.

15 Como señala Rorty (1998: 106) al diluir la frontera entre la justicia y la lealtad, «según las cosas se ponen más feas, los lazos de la lealtad con los que nos son cercanos se estrechan, mientras que los que nos unen con los lejanos se alejan". Nuestro interés en este punto radica en observar que esta continuidad entre justicia y lealtad puede mostrarse como especialmente relevante en los fenómenos de conflicto racial, pues en ellos adquiere carácter fundamental el sentimiento hacia y la representación del «nosotros».
}

16 Es de recordar aquí cómo para Brubaker (1992) la ciudadanía no debe verse sólo como un instrumento de participación e integración, sino también como un medio de cierre social y exclusión, pues el sistema que vincula la nacionalidad y ciudadanía tiene como correlato la definición de la extranjería y la articulación de políticas de control de la inmigración. Por su parte, llevando al extremo su tesis de la dialéctica de civilidad y barbarismo subyacente a todo discurso político, Smith (1998: 133) afirma: «las semillas de una cultura política totalitaria residen en los conceptos y los significantes de la propia sociedad civil: un cambio de énfasis aquí, una inversión de codificación allá y el demócrata se convierte en fascista». 
Como muestran muchos estudios de la violencia racial (Wieviorka, 1992: 169s), la importancia de los elementos simbólicos en la categorización de la etnicidad en términos de comunidad amenazada es especialmente relevante en aquellos casos en los que -tal y como ocurrió en El Ejido- los sucesos se desencadenan a partir de un crimen o violación de mujeres, quizá porque la barrera sexual es el último tabú en la percepción de un orden social que se ve peligrar cuando las acciones de individuos de un grupo subordinado comienzan a franquear las fronteras establecidas de una vida social segregada ${ }^{17}$. Las lógicas de la inferiorización y de la diferenciación (analíticamente diferenciadas en el esquema teórico de Wieviorka) se entremezclan entonces en los discursos que acompañan a la legitimación de una violencia infrapolítica que precisa que los individuos que no necesariamente debieran ser visibles desde el punto de vista del mantenimiento de la desigualdad (objetivo de la lógica de la inferiorización: «el otro no es molesto en su miseria») pasen a serlo (lo que ocurre cuando el discurso de apoyo a la violencia recurre a la lógica de la diferenciación: «el otro debe ser identificado, reconocido y señalado»).

Por otra parte, calificar este episodio de violencia racial como un fenómeno de crisis quiere decir en nuestro contexto de análisis (Alexander, 2000: 215) que existe suficiente consenso en percibirlo como un suceso anómalo y contaminante que, además, por sus graves implicaciones, puede llegar a afectar al núcleo o centro simbólico de la sociedad. La percepción del carácter crítico de este fenómeno es lo que mueve tanto a desarrollar o reforzar controles institucionales como a movilizar discursos e imágenes en el mercado de los medios de comunicación y en los espacios de la vida pública donde se compite por la autoridad interpretativa. Esta competencia puede describirse como lo que en otro contexto denomina Bourdieu una «lucha de clasificaciones», lucha que pone especialmente de relieve la problematicidad de la integración simbólica de la sociedad.

Las dos narrativas cuya competencia se analiza aquí son precisamente ilustraciones de esfuerzos interpretativos por parte de una cierta élite de la sociedad civil (los intelectuales) que sintonizan con diferentes sectores de la misma. Tomanos como principal referente de cada uno de los discursos los trabajos de Azurmendi (2001) y Martínez Veiga (2001), considerados aquí como exponentes académicos de discursos rutilantes en el debate de la esfera pública. Denominaremos «exculpatorio» y "culpatorio» a los respectivos discursos por su diferente construcción evaluativa de la posición de la población mayoritaria y autóctona. El cuadro 2 ofrece un esquema de su examen comparativo y sistematiza la forma en que se estructuran los elementos análogos de ambos discursos de acuerdo con las características fundamentales de la semiótica binaria de la cultura de la sociedad civil anteriormente considerada.

17 En el caso de El Ejido, los sucesos registrados entre el 5 y el 7 de febrero se desencadenaron tras el asesinato de una joven a manos de un marroquí en tratamiento psiquiátrico. Pocas horas después se produjeron los primeros cortes de carreteras, a los que siguieron manifestaciones de protesta e incluso el saqueo de mezquitas, bazares o locutorios. 


\begin{tabular}{|c|c|c|c|}
\hline & & \multicolumn{2}{|c|}{ Discursos } \\
\hline & & Exculpatorio & Culpatorio \\
\hline \multirow[t]{2}{*}{ Códigos } & $\begin{array}{l}\text { positivo } \\
\text { (sagrado) }\end{array}$ & $\begin{array}{l}\text { trabajo } \\
\text { esfuerzo } \\
\text { inversión } \\
\text { austeridad } \\
\text { reconocimiento a los iguales }\end{array}$ & $\begin{array}{l}\text { actitud integradora } \\
\text { solidaridad universalista } \\
\text { antirracismo }\end{array}$ \\
\hline & $\begin{array}{l}\text { negativo } \\
\text { (profano) }\end{array}$ & $\begin{array}{l}\text { ocio } \\
\text { tribalismo } \\
\text { consumo ostentoso } \\
\text { superioridad } \\
\text { beatería progresista }\end{array}$ & $\begin{array}{l}\text { explotación } \\
\text { discriminación injustificada } \\
\text { racismo }\end{array}$ \\
\hline
\end{tabular}

El discurso exculpatorio, que gravita fuertemente en torno a la figura del agricultor esforzado que no entiende de razas ni de ideologías, sino de tesón y superación, y que no discrimina en su trato más que a quien considera que no hace lo que está en sus manos por "salir p'adelante», sintoniza con la imagen de la gente sana y humilde del campo como verdadera protagonista del milagro almeriense, una imagen muy cara al discurso, por ejemplo, de organizaciones como la COAG o ASAJA a la hora de exonerar a los agricultores de la acusación de racismo en sus prácticas de contratación. Por su parte, el discurso culpatorio sintoniza con el de muchas ONGs y sindicatos de clase que han denunciado el carácter racista de estas prácticas de selección y contratación de los trabajadores o de segregación residencial porque se basan en una correlación, sólo sostenible a partir de presupuestos racistas, entre ciertos grupos y su productividad o su conflictividad.

Ciertamente, como señala Wieviorka (1992: 167), «la violencia racista nunca surge de la nada social». En este sentido, ambos discursos reconocen el conflicto económico como piedra angular de su interpretación, pero lo hacen de diferente manera. El discurso exculpatorio lo presenta en clave culturalista, mientras que el discurso culpatorio lo hace en clave materialista. Así, para el primero, el hecho incuestionable de la explotación del trabajador inmigrante es secundario en cuanto a sus consecuencias frente al hecho, no menos incuestionable, de que este trabajador no comparte en la mayoría de los casos la cultura del trabajo propia del agricultor del Poniente almeriense. Esta diferencia cultural bloquea la integración porque impide la asimilación de la relación dominante entre el trabajo y la vida, relación que para el agricultor (propietario hoy, pero también inmigrante o colono en su momento) se ha urdido en la historia de un hombre «hecho a sí mismo como un ser desde y para el trabajo», por lo que es «su sociabilidad laboral lo que le proporciona el ámbito de las preocupaciones 
e incentivos». Esta centralidad del trabajo falta en los mecanismos de identidad de los trabajadores africanos, por cuanto su cultura se considera «más próxima al ocio» y más tendente a «privilegiar el trabajo [sólo] en cuanto es suficiente para adquirir el sustento diario», por lo que «cuanto menor sea su dureza más éxito social y reconocimiento poseerá la familia. Vender algo es siempre más incentivador que cavar la tierra» (Azurmendi, 2001: 306), y ello explica buena parte de la supuesta tendencia del trabajador inmigrante a desertar de su trabajo. El patrón ha hecho de la «capacidad autoperfectiva del trabajo» su valor esencial y «no entiende a qué vienen a su tierra esta clase de inmigrantes sin amor al trabajo» y sin disposición a repetir con «tesón, esfuerzo y espíritu de superación» (Azurmendi, 2001: 293, 308) la misma experiencia de autoexplotación que él se impuso. Dicho sea de paso, esta sensación de extrañeza ante una diferente valoración del trabajo y de los atributos del estilo de vida a ella asociados (austeridad, entrega, afán de progreso a través del trabajo, trato igualitario y estima para quien así trabaja) no sólo traza una distancia cultural frente al trabajador inmigrante, sino también frente a los descendientes autóctonos que no se movilizan según este mismo esquema, tanto si han de encargarse de la gestión de una propiedad (que no han levantado con sus manos) y de unos individuos (con los que no han trabajado codo a codo durante años) como si huyen de ella en una carrera de movilidad social adornada, generalmente, de una ostentosidad desconocida por su progenitor.

Por su parte, el discurso culpatorio se elabora también en torno a la centralidad del conflicto económico, pero así como el discurso exculpatorio considera que el racismo no ha tenido ningún valor funcional en la configuración del proceso de trabajo de los invernaderos, el discurso culpatorio mantiene una relación funcional entre racismo y explotación económica. Así, para Martínez Veiga (2001: 183-185), que la discriminación que sufren los trabajadores inmigrantes marroquíes se presente como estadística -es decir, que se presente como una simple preferencia del empleador por los trabajadores más productivos- no la hace menos discriminatoria y no hace, en el fondo, sino remitir a un «racismo enmascarado» (en expresión de Salomos y Back, 1999: 72). Después de todo, si se produce es porque existe una enorme bolsa de fuerza de trabajo a la espera; porque el trabajo a realizar es escasamente cualificado y fácilmente aprendible y, por tanto, exige una formación tan elemental que es fácilmente presuponible para todos; porque, entonces, el empleador tiende a tomar como criterio de selección otras cualificaciones de tipo más actitudinal; y porque, finalmente, recurre para su selección de estas cualificaciones más difícilmente observables a la estrategia de menos costes: la selección superficial basada en características externas, fácil y rápidamente detectables, como los rasgos raciales. Para el discurso culpatorio, pues, la razón por la que a las personas con ciertos rasgos se las asocia con el carácter conflictivo radica en el prejuicio racista, aunque éste se exprese en su versión culturalista, como cuando se dice que es la cultura de los magrebíes la que les impide adaptarse a la sociedad española. 
La diferente cultura del trabajo utilizada como variable fundamental por el discurso exculpatorio es asociada por éste a un ethos o conjunto de disposiciones para la vida igualmente distante del que han desarrollado los agricultores autóctonos. Este ethos se manifiesta en una diferente concepción de la dignididad humana, que en el caso del trabajador inmigrante (especialmente del marroquí) se manifiesta en el descuido de la limpieza personal y el acondicionamiento del alojamiento, lo que bloquea su integración y alimenta muchas de las representaciones de la población autóctona. El discurso culpatorio no es ciego a estas características asociadas al estilo de vida y la presentación en la vida pública, pero las reduce a efecto de una circunstancia de marginalidad debida a la discriminación laboral y la segregación residencial. No es que el discurso exculpatorio niegue la realidad de esta marginalidad, pero la considera superable, o cuando menos mejorable, si existiera ese impulso de dignidad que se considera probado en otros colectivos emigrantes, como el de los españoles en Europa o el de los propios patrones cuando emigraron al Poniente almeriense desde la Alpujarra.

La tercera gran diferencia entre ambos discursos tiene que ver con el papel atribuido al racismo en el desencadenamiento de los hechos. Tal y como se desprende de su conceptualización de la relación entre explotación económica y racismo, el discurso culpatorio habla de un racismo encarnado en las actitudes y las prácticas de la población autóctona reforzado, además, por la estructura del racismo institucional. Una ramificación de este racismo sería la tendencia observada por Martínez Veiga (2001: 174) a presentar el milagro de la agricultura almeriense como producto del esfuerzo de «padres y abuelos» de los autóctonos, tendencia que -además de ocultar el hecho de que sólo el $5 \%$ de los habitantes de El Ejido en el 2000 hayan nacido allí- implica un afán por reconocer una especie de derecho ancestral a la explotación de la tierra y de quien la trabaja. Podría verse aquí la construcción de una especie de «nacionalismo de vecindario» (Back, 1996; Terrén, 2002b) que elabora la historia sagrada de una «comunidad imaginada» ocultando en su narrativa el hecho profano o contaminado de que, en realidad —como sugiere otro exponente del discurso culpatorio (Castellanos y Pedreño, 2001) - , la historia del éxito de esta agricultura es la historia de la presencia continuada de mano de obra barata.

Por su parte, el discurso exculpatorio niega que el racismo sea una variable explicativa del acontecimiento: «ni el racismo ni la xenofobia son el problema de El Ejido» (Azurmendi, 2001: 287); y considera, además, que el recurrir al mismo es resultado de una producción mediática de significados sesgada artificialmente por «cierto abominable antirracismo que, para tener razón, precisa crear racistas a su derredor» o bien, en su versión más académica, por la reformulación multiculturalista de un cierto marxismo que necesita «suplir la lucha de clases contra el capitalismo por la lucha de las culturas contra el sistema» (Azurmendi, 2001: 343, 356). Esta posición sintoniza claramente con los ataques a la parcialidad 
de algunas ONGs y la «esquizofrenia» de algunos «escritores pseudoprogresistas» y medios de comunicación nacionales «que raudos están a difamar a nuestro pueblo, mas nunca, no ya a defenderlo, sino siquiera a comprenderlo», como se dijo en una manifestación que precedió al estallido del 5 de febrero ${ }^{18}$. Las diferentes interpretaciones de esta manifestación resultan ya de por sí ilustrativas de una diferente forma de enfocar la gestación del posterior episodio de violencia racial. Para Azurmendi, lo decisivo era una percepción de invasión e inseguridad que respondía a un fenómeno comprobado de sobreinmigración, percepción que podía dispararse en cualquier momento como violencia colectiva. Azurmendi, sin embargo, se esfuerza por hacer coexistir el estado latente de esta percepción con un antirracismo prevalente y utiliza las reivindicaciones de la manifestación como prueba. Martínez Veiga, en cambio, hace una descripción de la manifestación que muestra cómo lo verdaderamente latente — si no ya manifesto- era un racismo violento, cuando menos verbalmente.

Para el discurso exculpatorio son, pues, la beatería antirracista y la producción periodística de significados las responsables de la satanización de la población autóctona. En este discurso se niega que pueda encontrarse en ella algo parecido a una "configuración ideológica racista» porque ni siquiera se ha llegado a interiorizar la anteriormente referida «contradicción cultural del sistema productivo como odio al inmigrante» (Azurmendi, 2001: 308). Lo ocurrido no es, pues, consecuencia de un racismo latente en la población autóctona, sino producto de una explosión xenofóbica por ambas partes. Para la primera de las partes, la explosión fue estimulada simplemente por un sentimiento de que, frente a la «invasión» percibida y la inseguridad galopante, los políticos les habían abandonado y la ley y la administración se mostraban ineficaces. La combinación de estas sensaciones de invasión e inseguridad es lo que provocó «un cierto cierre etnocéntrico frente al "moro"» (Azurmendi, 2001: 339). En la raíz de la explosión xenofóbica de la otra parte, la de los inmigrantes, el discurso exculpatorio encuentra también un sentimiento, pero bien distinto: la frustración, derivada - al igual que su escasa disposición al trabajo esforzado- de la estructura cultural de su sociedad de procedencia o, más bien, del choque de la quimera del oro fácil con la tradición del orgullo tribal (Azurmendi, 2001: 173). En este caso, la frustración proviene de la percepción de que el trabajo y la vida que les ofrece el Poniente almeriense no es la que esperaban ni la que necesitan para ser reconocidos como «un pariente excelente» entre los suyos: «trabaje o no, la insatisfacción será su primer peldaño», tanto más elevado cuanto más tarde en darse cuenta de que la presión que sufre para el triunfo social sólo podrá aliviarse «desde su capacidad para cambiar él como persona y dar por zanjada culturalmente su particular ensoñación de personaje tribal». Cuando este cambio no se produ-

18 Palabras del manifiesto leído en la manifestación del 30.01.2000, una semana después del asesinato de dos agricultores a manos de un marroquí (apud La Voz de Almería, 31.01.2000, cit. en Martínez Veiga, 2001: 194). 
ce, es cuando «la frustración abre vías al resentimiento y también al odio a España» (Azurmendi, 2001: 303s).

El examen de los fenómenos preparatorios de los acontecimientos de febrero presentado por el discurso culpatorio de Martínez Veiga (2001: 192ss) constata igualmente los sentimientos de impotencia y desprotección expresados públicamente por los agricultores almerienses, pero advierte en ellos una operación ideológica característica de lo que podríamos llamar una definición racialista de la situación: la transvaluación. Ésta consiste en abstraer fenómenos de sus circunstancias concretas y agregarlos — distorsionándolos-en un tópico más amplio, en este caso étnicamente relevante. Los fenómenos agregados en esta operación concreta fueron desde la actitud agresiva y amenazante percibida en la comercialización marroquí de sus productos agrícolas hasta la idéntica actitud percibida en los trabajores ilegales que pululan entre los invernaderos. La operación clasificatoria implícita en esta transvaluación llega igualmente a negar legitimidad a quienes —como es el caso de las ONGs - intentan trazar puentes que son percibidos como una traición a la comunidad. Éstas, como los «escritores pseudoprogresistas» anteriormente mencionados, pasan a ser clasificados al lado de la amenaza externa ${ }^{19}$ en una maniobra de identificación que se nutrió de (y al mismo tiempo nutrió a) un sentimiento de abandono e indefensión abonado por las movilizaciones de los dos mes anteriores (la «guerra del tomate»), si bien entonces el objeto no era tanto la invasión de marroquíes como la de sus productos agrícolas en el mercado europeo. El mensaje, en cualquier caso, era claro: «unirse desde dentro para enfrentarse a algo que viene de fuera» (Martínez Veiga, 2001: 190).

Como se ve, la dirección explicativa de ambos discursos es claramente inversa. Para el discurso exculpatorio, el racismo no existía antes sino después de los acontecimientos, «al haberse delimitado dos colectivos mutuamente distantes» (Azurmendi, 2001: 339). Para el discurso culpatorio, en cambio, el racismo era algo ya latente en la organización social del Poniente almeriense y, sobre todo, una variable explicativa fundamental de su manifiesta segmentación étnica del mercado de trabajo. La dirección contrapuesta de ambas interpretaciones se muestra en el diferente uso que hacen de una misma herramienta analítica: el cierre social. Para Azurmendi (2001: 338s, 323), el cierre fue sobre todo un cierre etnocéntrico resultado de un agrupamiento dualista, una autosegregación reactiva frente al aislamiento mediático y a la percepcion del peligro del otro. «Por encima de todo, está la percepción social de invasión», de la que el cierre es consecuencia. Para Martínez Veiga (2001: 214ss), en cambio, el racismo no es un «brote», pues el cierre social que lo explica

\footnotetext{
19 Con ayuda de la idea de la «lucha de clasificaciones» (Bourdieu, 2002: 14s) anteriormente mencionada, puede entenderse cómo, en la medida en que los productores institucionales de ambos discursos formaban parte de las fuerzas identificadas como "amenazantes», uno de los puntos clave de la competencia interpretativa ha sido precisamente el rechazo de las respectivas clasificaciones por quienes en cada caso se consideraban mal clasificados.
} 
no es tanto una respuesta puntual cuanto una estrategia que soporta tendencias estructurales como la segmentación del mercado de trabajo o la segregación espacial (tan importante a la hora de entender el desconocimiento mutuo y los miedos propagados por los rumores). El cierre no es aquí tanto una reacción al estallido desencadenado por un estímulo que activa el miedo cuanto un elemento consustancial a una estructura de clases que precisa de operaciones ideológicas para legitimar el acceso diferencial a recursos y privilegios. El esquema marxista de esta interpretación de la relación entre capitalismo y racismo (muy dependiente de Williams, 2000) permite integrar los acontecimientos que Azurmendi califica de «explosión» en una perspectiva que los categoriza como «ritual», es decir, como celebración o reproducción de algo ya dado estructuralmente.

A ambas interpretaciones subyace una visón análogamente contrapuesta de una misma meta social: la integración. Así, en los términos del discurso exculpatorio, puesto que considera probada la disposición del autóctono a facilitar la integración del inmigrante, ésta pasa a gravitar fundamentalmente sobre las disposiciones de carácter del inmigrante: en concreto, sobre su intención de vivir una vida digna y su capacidad para modificar su estilo de vida haciéndolo converger con el del autóctono (Azurmendi, 2001: 345, 347). En los términos del discurso culpatorio, en cambio, la integración social sólo es alcanzable si se supera la fractura social que condena a la exclusión social y a la dinámica de un mercado sin reglas a quienes sólo son reconocidos por los empleadores como mercancía productora de mercancías y por la administración como meros objetos de una fallida política de inmigración.

\section{CONCLUSIONES}

El objeto del análisis comparativo presentado en la última sección de este trabajo no es evaluar cuál de las interpretaciones suministradas por las dos narrativas aquí consideradas es más satisfactoria, sino apreciar cómo en ambas se reproduce un código semiótico idénticamente binario que, tal y como se expuso en las dos primeras secciones, puede considerarse como propio de la estructura simbólica de la cultura política de la sociedad civil. En el plano de mayor abstracción, el estudio de las narrativas que pugnan por la interpretación de un conflicto crítico parece ofrecer gran potencial analítico al estudio de la construcción de la solidaridad desde la perspectiva de una sociología cultural enmarcada en una teoría sociológica de lo sagrado. Más concretamente, el análisis presentado parece confirmar que los discursos de la ciudadanía que proporcionan narrativas a un fenómeno de conflicto racial reproducen la ironía que subyace a la producción de la solidaridad. Esta ironía deriva del hecho de que, debido al carácter estructuralmente binario de su simbología, dichas narrativas albergan una tensión inherente entre inclusión y exclusión pues, junto con las pro- 
puestas morales y cognitivas en las que basan sus estrategias de identificación y pertenencia, parecen verse obligadas a producir al mismo tiempo su antítesis; es decir, no parecen ser capaces de representar la virtud y generar lealtad si no es representando también lo que se considera anticivil y amenazante para la comunión social.

En el discurso exculpatorio, la civilidad sacralizada se estructura simbólicamente con los signos que emergen de la figura del «Titán encadenado» que «volvió verde lo que era tierra de fuego» (Azurmendi, 2001: 109), que protagonizó el milagro de la agricultura almeriense y que ama a quien trabaja como él. El amigo legitimado es el que asimila la cultura del trabajo encarnada por este Titán, el héroe de la narrativa exculpatoria. Por otro lado, la barbarie contaminante es la de quienes viven ajenos a o distantes de la vida cotidiana de la comunidad y, muy especialmente, de la cultura y la sociabilidad del trabajo y el esfuerzo que supuestamente les caracteriza. Es la barbarie o la fuerza contaminante que traen consigo los marroquíes que no quieren trabajar en lo que hay, echar raíces y prosperar, sino ganar dinero y marchar; la de los nuevos ricos herederos que no han labrado la riqueza con sus manos y buscan el reconocimiento más en el fácil prestigio que otorga el consumo ostentoso que en el difícil prestigio que confiere el reconocimiento a una biografía de esfuerzo; y es, sobre todo, la barbarie de los reporteros ávidos de racismo a los que se atribuye una actitud desmedida e interesada por anatemizar a una comunidad antes de conocerla. También el discurso culpatorio parece reproducir, por su parte, la misma dialéctica del amigo y el enemigo. La politeya sacralizada por el código es, en este caso, la basada en una sociabilidad regida por la igualdad de trato, relación que aparece simbolizada en el altruismo de algunas organizaciones y en la denuncia de ciertos intelectuales y sindicatos. El enemigo deslegitimado es el racista que discrimina sin arreglo a más ley que su interés y sin más amparo que la legitimación de la mayoría.

En definitiva, parece que la organización interna de los elementos discursivos clave recogidos en el cuadro 2 muestra, efectivamente, cómo tanto la narrativa del discurso exculpatorio como la del culpatorio pueden considerarse como acciones lingüísticas o «textos» que producen significaciones concretas dentro de una estructura simbólica subyacente: el código semiótico basado en la contraposición de elementos civiles y anticiviles que pueden sistematizarse de acuerdo con el binarismo fundamental de la sociología cultural durkheimiana anteriormente presentada. En virtud de este código, ambas narrativas son capaces de producir imágenes y movilizar emociones que alimentan la identificación con una comunidad imaginada y sacralizada y producen dos versiones de la solidaridad social que emana de la sociedad civil: la una lo hace a través del sentimiento del miedo, que exonera al habitante autóctono de la responsabilidad del conflicto y lo constituye bajo la figura del héroe victimizado; la otra lo hace a través del sentimiento del odio, que culpabiliza al autóctono y victimiza al recién llegado. En tanto que fuentes de afecto o desafecto, tanto el miedo como 
el odio muestran claramente una tensa relación de implicación entre la solidaridad social que alimentan y la clasificación social sobre la que se basan. En esta relación se basa una de las fuentes de tensión y ambivalencia que registra el universalismo propio de la vida cultural de una sociedad civil cuyo discurso parece estructuralmente obligado a representar la inclusión y la exclusión a un mismo tiempo.

Si es cierto que, como subrayó el Informe Ford sobre el racismo, «es en el ámbito de la cultura en el que se elaboran y reelaboran las imágenes que después pueden constituir la base del éxito de la propaganda y las actitudes del racismo declarado, o también de su fracaso» (Ford, 1991: 221), el marco teórico desarrollado en este trabajo debe haber permitido ver cuál es la base estructural de la cultura sobre la que se produce esa elaboración y cómo lo sagrado se constituye como un foco de diferencia. El consustancial binarismo en el que se produce lo sagrado sería lo que permitiría explicar el fácil encaje narrativo que tienen tanto los pares dicotómicos sobre los que tiende siempre a gravitar la producción discursiva en torno al conflicto racial (de aquí/de afuera, civilización/barbarie, amigo/enemigo) como las metáforas que subrayan la amenaza que conlleva la profanación de las fronteras asociándola con la contaminación o el contagio («marea», «avalancha», «peste») (Santamaría, 2002).

Parece mostrado, así, cómo, efectivamente, el análisis de la producción discursiva de la sociedad civil sobre un conflicto racial constituye un terreno empírico abonado para observar el problema teórico subyacente, que es la tensa relación existente entre clasificación y solidaridad. Permite mostrar cómo ese ámbito de sociabilidad idealizado por las cualidades del código de lo sagrado es llevado a la práctica a través de narrativas que la reelaboran como una «comunidad imaginada», por utilizar la feliz expresión de Benedict Anderson, en un lenguaje de fronteras simbólicas. Los símbolos sacralizados por el código son algo más que la cara positiva de una polarización abstracta; son una fuente de los sentimientos y las emociones sin los que los individuos no pueden adoptar una actitud comprometida hacia los demás, sentimientos y emociones sin los que no existiría el vínculo afiliativo en que descansa la solidaridad social. Toda simbolización de lo sagrado o lo puro, del tipo de comunidad moral que en nuestra sociedad moderna y democrática — según lo visto en el cuadro 1- podríamos considerar como el código de la religión civil, se clasifica al lado de signos de impureza que revisten un carácter contaminante y, por ende, amenazante. Sólo en esta irónica compañía es capaz de ser narrada en un discurso que inspire la lealtad que precisan las vinculaciones afiliativas de la comunión social. En esta tozuda persistencia de lo binario es en donde parece radicar la ironía de la solidaridad. 


\section{BIBLIOGRAFÍA}

ALEXANDER, J. (1988): «Durkheimian sociology and cultural studies today», en ídem (ed.), Durkheimian sociology: cultural studies, Cambridge: Cambridge University Press, pp. 1-22.

- (1990): «Analytic debates: understanding the relative autonomy of culture», en ídem (ed.), Culture and society: contemporary debates, Cambridge: Cambridge University Press, pp. 1-30.

— (1997): «The paradoxes of civil society», International Sociology, 12 (2): 115-133.

— (ed.) (1998): Real civil societies: dilemmas of institutionalization, Londres: Sage/ISA.

- (2000): Sociología cultural, Barcelona: Anthropos.

- (2000a): «Sociología cultural o sociología de la cultura: hacia un programa fuerte», en ídem (2000: 32-54).

- (2000b): «Ciudadano y enemigo como clasificación simbólica: sobre el discurso polarizador de la sociedad civil», en ídem (2000: 141-164).

AZURMENDI, M. (2001): Estampas de El Ejido. Un reportaje sobre la integración del emigrante, Madrid: Taurus.

BACK, L. (1996): New ethnicities and urban culture: racisms and multiculture in young lives, Londres: University College.

BELLAH, R. (1970): “Civil religion in America», en ídem, Beyond belief. Essays on religion in a post-traditional world, Nueva York: Harper and Row.

BOURDIEU, P. (2002): Lección sobre la lección, Barcelona: Anagrama.

BRUBAKER, R. (1992): Citizenship and natiohood in France and Germany, Cambridge (Mass.): Harvard University Press.

CALHOUN, C. (1993): «Nationalism and civil society: democracy, diversity and self-determination», International Sociology, 8 (4): 387-412.

CALVO BUEZAS, T. (2001): Inmigración y racismo. Así sienten los jóvenes del siglo XXI, Madrid: Cauce Editorial.

CASTELLANOS, M. L., y PEDREÑO, A. (2001): «Desde El Ejido al accidente de Lorca», Sociología del Trabajo, 42: 3-32.

DOUGLAS, M. (1966): Purity and danger, Londres: Routledge \& Keegan.

DURKHEIM, E. (1893/1982): La división del trabajo social, Madrid: Akal.

- (1912/1982): Las formas elementales de la vida religiosa, Madrid: Akal.

ECRI (1999): Informe sobre España, Estrasburgo: Consejo de Europa (Comisión Europea contra el Racismo y la Intolerancia).

EMIRBAYER, M. (1996): «Useful Durkheim», Sociological Theory, 14 (29): 109-130.

FORD, J. G. (1991): Informe Ford sobre el racismo en Europa, Madrid: Ministerio de Asuntos Sociales.

GAVIRIA, M. (2001): «El Ejido: la fiebre del plástico: ¿Le quedan 20 años de vida? », en SOS Racismo, Informe anual 2001, Barcelona: Icaria, pp. 100-104.

GEERTZ, C. (1989): La interpretación de las culturas, Barcelona: Gedisa. 
GIDDENS, A. (1993): Consecuencias de la modernidad, Madrid: Alianza.

GINER, S. (1996): «La religión civil», en R. Díaz Salazar (et al.), Formas modernas de religión, Madrid: Alianza, pp. 129-171.

JACOBS, R. (1996): «Civil society and crisis: culture, discourse and the R. King beating», American Journal of Sociology, 101 (5): 1258-1272.

JOAS, H. (1998): «Durkheim y el pragmatismo. La psicología de la consciencia y la constitución social de las categorías», en El pragmatismo y la teoría de la sociedad, Madrid: CIS.

KUMAR, K. (1993): «Civil society: an inquiry into tha usefulklness of an historical term», British Journal of Sociology, $44(3): 375-395$.

MARTíNEZ VEIGA, U. (2001): El Ejido: discriminación, exclusión social y racismo, Madrid: Los Libros de la Catarata.

NASH, K. (2001): «The "cultural turn" in sociological theory», Sociology, 35 (1): 71-92.

PARK, R. E. (2002/1939): «La naturaleza de las relaciones raciales», en E. Terrén (ed.), Razas en conflicto: perspectivas sociológicas, Barcelona: Anthopos, pp. 104-124.

PÉREZ DÍAZ, V. (1998): «The public sphere and a European civil society», en J. Alexander (ed.), pp. 211-238.

RAMOS TORRE, R. (1999): La sociología de Émile Durkheim, Madrid: CIS.

RICOEUR, P. (1971): «The model of a text: meaningful action considered as a text», Social Research, 38: 529-562.

RORTY, R. (1998): «La justicia como lealtad ampliada», en ídem, Pragmatismo y política, Barcelona: Paidós, pp. 105124.

SALOMOS, J., y BACK, L. (1999): «Marxism, racism and ethnicity», en R. Torres, L. Miron y J. Inde (eds.), Race, identity and citizenship, Oxford: Blackwell.

SANTAMARÍA, E. (2002): La incógnita del extraño. Una aproximación a la significación sociológica de la «inmigración no comunitaria», Barcelona: Anthropos.

SHILS, E. (1975): Center end periphery: esays in macrosociology, Chicago: University of Georgia Press.

SMITH, Ph. (1998): «Barbarism and civility in the discourses of fascism, communism and democracy: variations on a set of themes», en J. Alexander (ed.) (1998), pp. 115-137.

SWIDLER, A. (1986): «Culture in action: symbols and strategies», American Sociological Review, 51: 273-286.

TERRÉN, E. (2002a): «El análisis de la cuestión racial en el desarrollo de la sociología», Introducción a E. Terrén (ed.), Razas en conflicto: perspectivas sociológicas, Barcelona: Anthropos, pp. 5-41.

- (2002b): «La etnicidad y sus formas: aproximación a un modelo complejo de la pertenencia étnica», Papers, 64: 43-52.

WEBER, M. (1974): Economía y sociedad, México: Fondo de Cultura Económica.

WIEVIORKA, M. (1992): El espacio del racismo, Barcelona: Paidós.

WILLIAMS, J. (2000): «Race and class: why all the confusion?, en B. Lang (ed.), Race and racism in theory and pactice, Langham: Rowan and Littlefield. 


\section{ABSTRACT}

The aim of this paper is to explore the analytic potential of a neodurkheimian cultural sociology in understanding how civil society reacts to a phenomenon of racial conflict (namely the riots at El Ejido in February 2000). The paper claims that different narratives arising from civil society share a common semiotic code structured on a dichotomized classification representing inclusion and exclusion at the same time. This binary code is taken as the deep symbolic structure of the civil society discourse. The analysis of competing narratives from the point of view of a cultural sociology centered on the symbolic processes underlying civil religion shows what is called the «irony of solidariry»: the production of feelings and loyalties on which social solidarity is dependent cannot take place without a polarized classification of «we-ness» and «other-ness». This representation provides a deep grammar of polarized categories which give shape to the discourse of civil society on racial conflict on the basis of pure/impure, sacred/profane distinction. 